\title{
Mechanical contributors to sex differences in idiopathic knee osteoarthritis
}

\author{
Daniel P Nicolella ${ }^{1,2^{*}}$, Mary I O'Connor ${ }^{1,3}$, Roger M Enoka ${ }^{1,4}$, Barbara D Boyan ${ }^{1,5}$, David A Hart ${ }^{1,6}$, Eileen Resnick', \\ Karen J Berkley ${ }^{1,7}$, Kathleen A Sluka ${ }^{1,8}$, C Kent Kwoh ${ }^{1,9}$, Laura L Tosi ${ }^{1,10}$, Richard D Coutts ${ }^{1,11}$, Lorena M Havill ${ }^{1,12}$ \\ and Wendy M Kohrt ${ }^{1,13}$
}

\begin{abstract}
The occurrence of knee osteoarthritis $(\mathrm{OA})$ increases with age and is more common in women compared with men, especially after the age of 50 years. Recent work suggests that contact stress in the knee cartilage is a significant predictor of the risk for developing knee OA. Significant gaps in knowledge remain, however, as to how changes in musculoskeletal traits disturb the normal mechanical environment of the knee and contribute to sex differences in the initiation and progression of idiopathic knee OA. To illustrate this knowledge deficit, we summarize what is known about the influence of limb alignment, muscle function, and obesity on sex differences in knee OA. Observational data suggest that limb alignment can predict the development of radiographic signs of knee OA, potentially due to increased stresses and strains within the joint. However, these data do not indicate how limb alignment could contribute to sex differences in either the development or worsening of knee OA. Similarly, the strength of the knee extensor muscles is compromised in women who develop radiographic and symptomatic signs of knee OA, but the extent to which the decline in muscle function precedes the development of the disease is uncertain. Even less is known about how changes in muscle function might contribute to the worsening of knee OA. Conversely, obesity is a stronger predictor of developing knee OA symptoms in women than in men. The influence of obesity on developing knee OA symptoms is not associated with deviation in limb alignment, but BMI predicts the worsening of the symptoms only in individuals with neutral and valgus (knockkneed) knees. It is more likely, however, that obesity modulates OA through a combination of systemic effects, particularly an increase in inflammatory cytokines, and mechanical factors within the joint. The absence of strong associations of these surrogate measures of the mechanical environment in the knee joint with sex differences in the development and progression of knee OA suggests that a more multifactorial and integrative approach in the study of this disease is needed. We identify gaps in knowledge related to mechanical influences on the sex differences in knee OA.
\end{abstract}

Keywords: Knee joint, Limb alignment, Muscle function, Obesity, Osteoarthritis, Sex differences

\section{Review}

As discussed in the preceding introduction to our series of papers, the exact etiology of knee osteoarthritis (OA) is not well understood. One prominent theory on the mechanisms underlying the development of knee OA attributes a primary role to perturbations of the local

\footnotetext{
* Correspondence: dnicolella@swri.org

'Isis Research Network on Musculoskeletal Health, Society for Women's

Health Research, Washington, DC 20036, USA

${ }^{2}$ Mechanical Engineering Division, Southwest Research Institute, San Antonio,

TX 78238, USA

Full list of author information is available at the end of the article
}

mechanical environment [1], especially the loads experienced by the articular cartilage. Recent computational studies, for example, have indicated that the risk of developing a combination of symptoms and radiographic signs of knee OA at 15 months after a baseline evaluation can be predicted by estimates of the contact stress on the cartilage during a static standing position [2]. Individual differences in joint mechanics, therefore, are presumed to contribute significantly to the degradation of the cartilage during idiopathic knee OA [3].

Three prominent risk factors for the development and worsening of knee $\mathrm{OA}$ are limb alignment, muscle

\section{Biomed Central}


weakness, and obesity, all of which alter the mechanical environment of the joint. However, not all individuals who present with these risk factors develop knee OA and, conversely, many individuals who do not exhibit these risk factors develop OA in later years [4]. Consequently, the hypothesis has emerged that differences in joint mechanics, driven by normal variability in joint anatomy and biological predisposition, underlie much of the variation in risk of knee OA onset and progression. However, there are no effective means of identifying which of those individuals who present with these risk factors will develop knee OA.

Understanding how local mechanical stress in the knee joint contributes to knee OA is key to developing intervention strategies to minimize the development and worsening of the disease. However, it is difficult to measure the mechanical environment of the cartilage in vivo and the use of computational methods to estimate cartilage stresses is not practical in clinical settings. Consequently, the typical approach has been to use clinically measureable surrogates, such as musculoskeletal traits, that influence in vivo cartilage stress. Significant gaps in knowledge remain as to how sex differences in limb alignment, muscle function, and obesity disturb the normal mechanical environment of the knee and cartilage and thereby underlie sex differences in knee OA. To illustrate this deficit in knowledge, we summarize what is known and not known about how limb alignment, muscle function, and obesity influence sex differences in the development and worsening of knee OA. Other mechanical factors may be associated with the development of knee OA, but these are not addressed in this brief review.

\section{Limb alignment}

Limb alignment, measured as the hip-knee-ankle angle from a full-length radiograph, is characterized as valgus (knock-kneed), varus (bow-legged), or neutral. Varus limb alignment shifts the center of pressure within the knee medially and increases the external knee adduction moment during gait, which results in a greater proportion of the load being borne by the medial compartment of the contact between the femur and tibia (e.g., medial condyles) [5]. Conversely, valgus limb alignment shifts the center of pressure laterally and reduces the external adduction moment about the knee during gait, which increases lateral-compartment loading (e.g., lateral condyles) (Figure 1). The influence of limb alignment on the distribution of the load in the knee joint, and consequently the local mechanical environment of the cartilage during movement, is presumed to be a significant

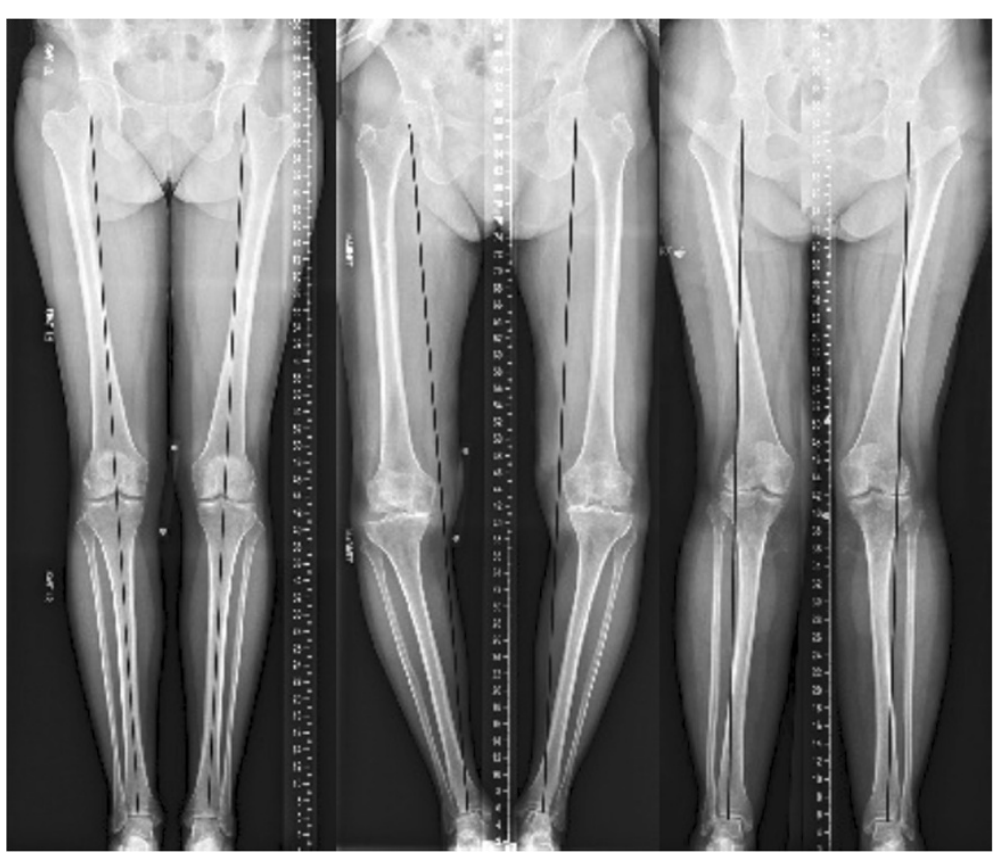

Figure 1 Full-length radiographs of both lower extremities showing neutral (left), varus (middle), and valgus (right) limb alignment. A line is drawn on each image from the center of the femoral head (representing the center of the hip joint) to the center of the ankle joint (talus). Left. When the line transects the knee joint, as in the neutral alignment, the weight-bearing stresses are well distributed in the lower extremity. Middle. When the line is medial to the center of the knee joint (varus alignment), there is an abnormal distribution of weight-bearing stresses on the medial (inner) aspect of the knee joint. Right. Conversely, when the line is located lateral to the center of the knee joint (valgus alignment), the weight-bearing stresses are greater on the lateral aspect of the knee joint. 
contributor to the erosion of cartilage, which is a fundamental characteristic of knee OA [6].

Despite the presumed negative influence of deviations in limb alignment from neutral, an observational study of 250 healthy adults (20-27 years) found that $32 \%$ of men and $17 \%$ of women had varus alignment (mechanical axis alignment of $\geq 3$ degrees from neutral) at skeletal maturity, which has been termed 'constitutional varus' [7]. There are no data on how this alignment influences either the development or progression of knee OA. In addition, limb alignment may not be symmetric within an individual, which may lead to unilateral development of knee OA due to differences in knee-joint loading between the left and right limbs. However, sex differences in unilateral vs. bilateral limb alignment and the subsequent role in the risk of incidence and progression of knee OA have not been examined and represent a significant gap in knowledge.

\section{Limb alignment and the development of knee $O A$}

Because limb alignment is relatively easy to measure in vivo, its relation with knee OA has been examined in a number of studies. In the longitudinal Multicenter Osteoarthritis Study (MOST), an investigation of 2,958 knees without radiographic evidence of knee OA at baseline but with frequent symptoms consistent with knee OA or at risk for developing knee OA, found that the risk of developing radiographic evidence of knee OA at 30 months after an initial evaluation was significantly elevated in individuals with varus knee alignment compared with neutral knee alignment (OR 1.49), whereas valgus alignment did not influence the risk of developing knee OA (OR 0.87) [8]. When limb alignment was considered as a continuous variable, the risk of developing knee OA was related to the magnitude of misalignment for varus limbs; a greater severity of varus alignment at baseline was associated with a higher risk of radiographic signs of knee OA. There was no such relation for valgus alignment. Furthermore, there were no sex differences in the risk of developing radiographic evidence of knee OA due to limb alignment. Similarly, varus alignment was associated with a 2 -fold increase in risk of developing radiographic signs of knee OA compared with a neutral knee alignment in the Rotterdam study of 1,501 participants (2,664 knees), whereas valgus alignment was associated with a 1.5-fold increase of developing knee OA risk [9]. The results were not influenced by the sex of the participants. Conversely, there was no association between limb alignment and the development of radiographic signs of knee OA over $\sim 9$ years in the Framingham cohort, although this study estimated limb alignment from X-rays of the knee and compared the most varus knees with the most valgus knees [10].

\section{Limb alignment and the progression of knee $O A$}

When there was radiographic evidence of knee $O A$ at baseline in the MOST study, those knees in a limb with varus alignment were at significantly greater risk for a worsening of the radiographic signs in the medial compartment at 30 months (OR 3.59), whereas knees in a limb with valgus alignment at baseline were at greater risk for an increase in the radiographic signs of OA in the lateral compartment at 30 months [8]. There were no sex differences in either association. Conversely, only those participants in the Rotterdam study with varus alignment of the limb experienced a significant increase in risk of the radiographic signs of knee OA becoming worse [9]. These observations were not categorized by either the compartment in which the radiographic evidence was observed or the sex of the participants.

Taken together, these data suggest that limb alignment is a predictor of both the appearance and worsening of radiographic signs of knee OA and that varus and valgus alignment each increase the risk of the radiographic evidence becoming more severe in the compartment that experiences an increase in the load transmitted through the joint. However, the association between limb alignment and cartilage stress is relatively modest because the stress depends on the geometry of the opposing joint surface, the material properties of the tissues (e.g., the stiffness of the ligaments, menisci, cartilage, and subchondral bone), and the forces acting across the knee joint. To examine these associations in more detail, patient-specific predictions of cartilage stress when standing on a single leg were simulated with a finite element model. The simulations indicated that the cartilage stress and strain in the medial compartment was greater for an individual with varus alignment, whereas the cartilage stress and strains in the lateral compartment were greater when the limb exhibited a valgus alignment (Table 1) [11]. The results from this computational study are consistent with the hypothesis that deviation of the limb from a neutral alignment has a direct influence on cartilage stress in vivo and can likely contribute to the development of knee OA and the rate at which the disease progresses.

Despite a probable role for limb alignment in contributing to the initiation and progression of knee OA, sex differences in lower limb alignment are equivocal (Table 2) [5,12-16]. Some of this uncertainty can be attributed to differences across studies in the methods used to assess limb alignment [17], the confounding influence of ethnicity on limb alignment, changes in limb alignment across the lifespan, and the relation of limb alignment during standing with such dynamic actions as walking. In summary, there is no obvious sex difference in the influence of limb alignment on knee OA among older adults, despite the greater prevalence of knee OA 
Table 1 The influence of limb alignment on the normal stress (relative to body weight) and strain for the medial (top) and the lateral (bottom) cartilage of the tibia and femur during the gait cycle

\begin{tabular}{llccc}
\hline & \multicolumn{2}{c}{ Medial Cartilage Normal Stress } & \multicolumn{2}{c}{ Medial Cartilage Normal Strain } \\
\hline Subject & Tibia & Femur & Tibia & Femur \\
\hline 1 (varus) & 0.020 & 0.023 & 18.66 & 26.66 \\
\hline 2 (normal) & 0.017 & 0.020 & 17.01 & 20.67 \\
\hline 3 (valgus) & 0.016 & 0.018 & 14.99 & 16.16 \\
\hline & Lateral Cartilage Normal & Stress & Lateral Cartilage Normal Strain \\
\hline Subject & Tibia & Femur & Tibia & Femur \\
\hline 1 (varus) & 0.001 & 0.003 & 4.64 & 6.79 \\
\hline 2 (normal) & 0.003 & 0.004 & 8.06 & 11.41 \\
\hline 3 (valgus) & 0.008 & 0.010 & 9.22 & 11.38 \\
\hline
\end{tabular}

The data were obtained at $25 \%$ of the stance phase when both the axial load and the varus knee moment were at peak values. The results showed the magnitude of the stresses and strains in the medial compartment increased with varus alignment, whereas the magnitude of the stresses and strains in the lateral compartment increased with valgus alignment [61].

among women in this age group $[5,16]$. We have identified several gaps in knowledge related to the influence of limb alignment on the sex differences in knee OA (Table 3).

\section{Muscle function}

Because the forces exerted by the muscles in the entire limb contribute to the contact forces experienced by the tissues that comprise the knee joint [17], questions arise regarding the extent to which changes in muscle function can modify the integrity of the knee joint and whether there are differences between men and women.

\section{Muscle strength as a predictor of the development of knee OA}

Cross-sectional studies suggest that weakness of the knee extensor muscles may precede the development of knee OA [18,19]. However, results from prospective

Table 2 Distributions of limb alignment by age, sex, and ethnicity

\begin{tabular}{|c|c|c|c|c|c|}
\hline Limb alignment measure & Ethnicity & Sex & Age (years) & Alignment Mean $\pm S D$ & Source Note/conclusion \\
\hline \multirow{4}{*}{$\begin{array}{l}\text { Femur-tibia angle (FTA) } \\
\text { (degrees, mean } \pm \text { SD) }\end{array}$} & \multirow[t]{4}{*}{ Not specified } & \multirow[t]{2}{*}{ men } & $21-40(n=30)$ & $2.3 \pm 2.3$ varus & \multirow{4}{*}{$\begin{array}{l}\text { [5] No age or sex differences Mean FTA } \\
1.2^{\circ} \pm 2.2^{\circ} \text { (varus) }\end{array}$} \\
\hline & & & $41-60(n=30)$ & $1.0 \pm 2.3$ varus & \\
\hline & & \multirow[t]{2}{*}{ women } & $21-40(n=30)$ & $1.3 \pm 1.8$ varus & \\
\hline & & & $41-60(n=30)$ & $0.3 \pm 2.3$ varus & \\
\hline \multirow[t]{2}{*}{ FTA (degrees, mean \pm SD) } & \multirow[t]{2}{*}{ Chinese } & men & $\begin{array}{l}\text { mean age: } 24 \\
\text { range: } 22-31(n=25)\end{array}$ & $2.2 \pm 2.7$ varus & \multirow[t]{2}{*}{ [15] No sex differences } \\
\hline & & women & $\begin{array}{l}\text { mean age: } 23 \\
\text { range: } 21-29(n=25)\end{array}$ & $2.2 \pm 2.5$ varus & \\
\hline \multirow[t]{6}{*}{ FTA (degrees, mean \pm SD) } & \multirow{6}{*}{$\begin{array}{l}\text { Japanese and } \\
\text { Australian Caucasian }\end{array}$} & \multirow[t]{3}{*}{ men } & $18-29(n=21)$ & $180.3 \pm 3.0$ varus & \multirow{6}{*}{$\begin{array}{c}\text { [16] In combined group, women had } \\
\text { more valgus alignment } p=0.017 \text { ) } \\
\text { Japanese (men and women) more varus } \\
\text { than Australian Caucasians; } \\
\text { No age effects }\end{array}$} \\
\hline & & & $30-59(n=36)$ & $179.8 \pm 2.5$ valgus & \\
\hline & & & $>60(n=23)$ & $180.0 \pm 2.1$ neutral & \\
\hline & & \multirow[t]{3}{*}{ women } & $18-29(n=35)$ & $179.5 \pm 3.2$, valgus & \\
\hline & & & $30-59(n=36)$ & $178.6 \pm 2.5$ valgus & \\
\hline & & & $>60(n=23)$ & $180.0 \pm 2.1$ neutral & \\
\hline \multirow[t]{2}{*}{$\begin{array}{l}\text { Hip-knee-Ankle (HKA) } \\
\text { (degrees, mean } \pm \text { SD) }\end{array}$} & \multirow[t]{2}{*}{$\begin{array}{l}\text { Not specified/ } \\
\text { Canadian }\end{array}$} & men & $\begin{array}{c}<30(n=38)>45 \\
(n=14)\end{array}$ & $-1.5 \pm 3.0$ varus & \multirow{2}{*}{$\begin{array}{l}\text { [13] Women more likely than men } \\
\text { in all age groups to have valgus } \\
\text { alignment ( } p=0.03 \text { ) No age effects }\end{array}$} \\
\hline & & women & $\begin{array}{c}<30(n=41)>45 \\
(n=26)\end{array}$ & $-0.5 \pm 2.6$ varus & \\
\hline \multirow[t]{4}{*}{ HKA } & \multirow[t]{4}{*}{$\begin{array}{l}\text { Japanese and } \\
\text { Caucasian }\end{array}$} & \multirow[t]{2}{*}{ men } & $\begin{array}{l}\text { Caucasian } 28 \pm 6.8 \\
\qquad(\mathrm{n}=23)\end{array}$ & $\begin{array}{l}36 \% \text { of men had } \\
\text { valgus alignment }\end{array}$ & \multirow[t]{4}{*}{$\begin{array}{l}\text { [14] Japanese higher varus vs. Caucasians } \\
\text { Women more valgus than men }\end{array}$} \\
\hline & & & $\begin{array}{c}\text { Japanese } 30 \pm 6.3 \\
(n=11)\end{array}$ & & \\
\hline & & \multirow[t]{2}{*}{ women } & $\begin{array}{l}\text { Caucasian } 26 \pm 7.7 \\
\qquad(\mathrm{n}=24)\end{array}$ & $\begin{array}{l}50 \% \text { women had } \\
\text { valgus alignment }\end{array}$ & \\
\hline & & & $\begin{array}{c}\text { Japanese } 37 \pm 6.2 \\
(n=12)\end{array}$ & & \\
\hline
\end{tabular}


cohort studies that assessed whether quadriceps strength predicts incident knee $\mathrm{OA}$ are equivocal. The longitudinal Multicenter Osteoarthritis Study (MOST) of 1,617 participants $(2,519$ knees) who did not exhibit radiographic signs of tibiofemoral $\mathrm{OA}$ at baseline found that neither knee extensor strength nor the relative strength of the hamstring muscles predicted incident radiographic (i.e., asymptomatic) evidence for tibiofemoral OA (48/680 men, 49 knees; 93/937 women, 99 knees) 30 months later [20]. The knee extensor strength for men and women who developed radiographic tibiofemoral OA (mean \pm SD) was $123 \pm 48$ and $74 \pm 29 \mathrm{~N} \cdot \mathrm{m}$, respectively, compared with $131 \pm 43$ and $76 \pm 25 \mathrm{~N} \cdot \mathrm{m}$ for those who did not (Figure 2). When women and men were grouped by tertiles of knee extensor strength, the odds ratios for incident radiographic OA in women and men with the highest strength levels (compared with the lowest) were 0.86 (CI: 0.65,1.14) and 0.76 (CI: $0.52,1.11)$, respectively.

In contrast, the same study found that knee extension strength was predictive of incident symptomatic (i.e., radiographic evidence plus symptoms) tibiofemoral OA. Out of 1,232 women and 846 men who did not have symptomatic tibiofemoral OA at baseline, 201 of 1,989 knees in women and 109 of 1,403 knees in men had incident symptomatic knee OA 30 months later. Knee extensor strength at baseline was $114 \pm 41 \mathrm{~N} \cdot \mathrm{m}$ for men who developed symptomatic OA compared with $130 \pm 42$ $\mathrm{N} \cdot \mathrm{m}$ for those who did not (Figure 3 ). In women, knee extensor strength at baseline was $65 \pm 26 \mathrm{~N} \cdot \mathrm{m}$ for those who developed symptomatic knee OA compared with 75 $\pm 25 \mathrm{~N} \cdot \mathrm{m}$ for those who did not (Figure 3). When women and men were grouped by tertiles of knee extensor strength, the odds ratios for incident symptomatic OA in women and men with the highest strength levels (compared with the lowest) were 0.7 (CI: 0.6,0.9) and 0.7 (CI: $0.5,0.9)$, respectively. Thus, the MOST study demonstrated that weak quadriceps strength was predictive of incident symptomatic, but not incident radiographic, tibiofemoral $\mathrm{OA}$ in both men and women.

\section{Muscle strength and the progression of knee $O A$}

Despite the finding that leg extensor strength was a determinant of incident symptomatic knee OA, it does not appear that strength influences the progression of OA. In a study of 111 women and 154 men with symptomatic knee OA who were followed for 30 months, there were no associations of quadriceps strength with the loss of cartilage at the tibiofemoral joint in either women or men, regardless of limb alignment [21]. Odds ratios in high- versus low-strength groups (women and men combined) for cartilage loss in the medial and lateral tibiofemoral compartments were 1.0 (CI: 0.5, 1.8) and 1.1 (CI: 0.5, 2.5), respectively. However, quadriceps strength was protective against cartilage loss in the lateral aspect of the patellofemoral joint (OR: 0.4; CI: $0.2,0.9)$. Greater quadriceps strength was also associated with less knee pain and better physical function, but analyses were not conducted separately in women and men. Similarly, among 57 women and 25 men with radiographic evidence of knee OA, only 14 women and 3 men were classified as having progressive OA when evaluated 31.5 months later. Knee extensor strength at baseline did not differ between those with progressive versus non-progressive OA [22].

\section{Muscle function and knee $O A$}

Because the contribution of muscle activity to the stresses experienced by knee-joint cartilage depends on how the muscles are used during dynamic actions, some knee OA studies have compared patterns of muscle activity in men and women when they walk. In one such study,

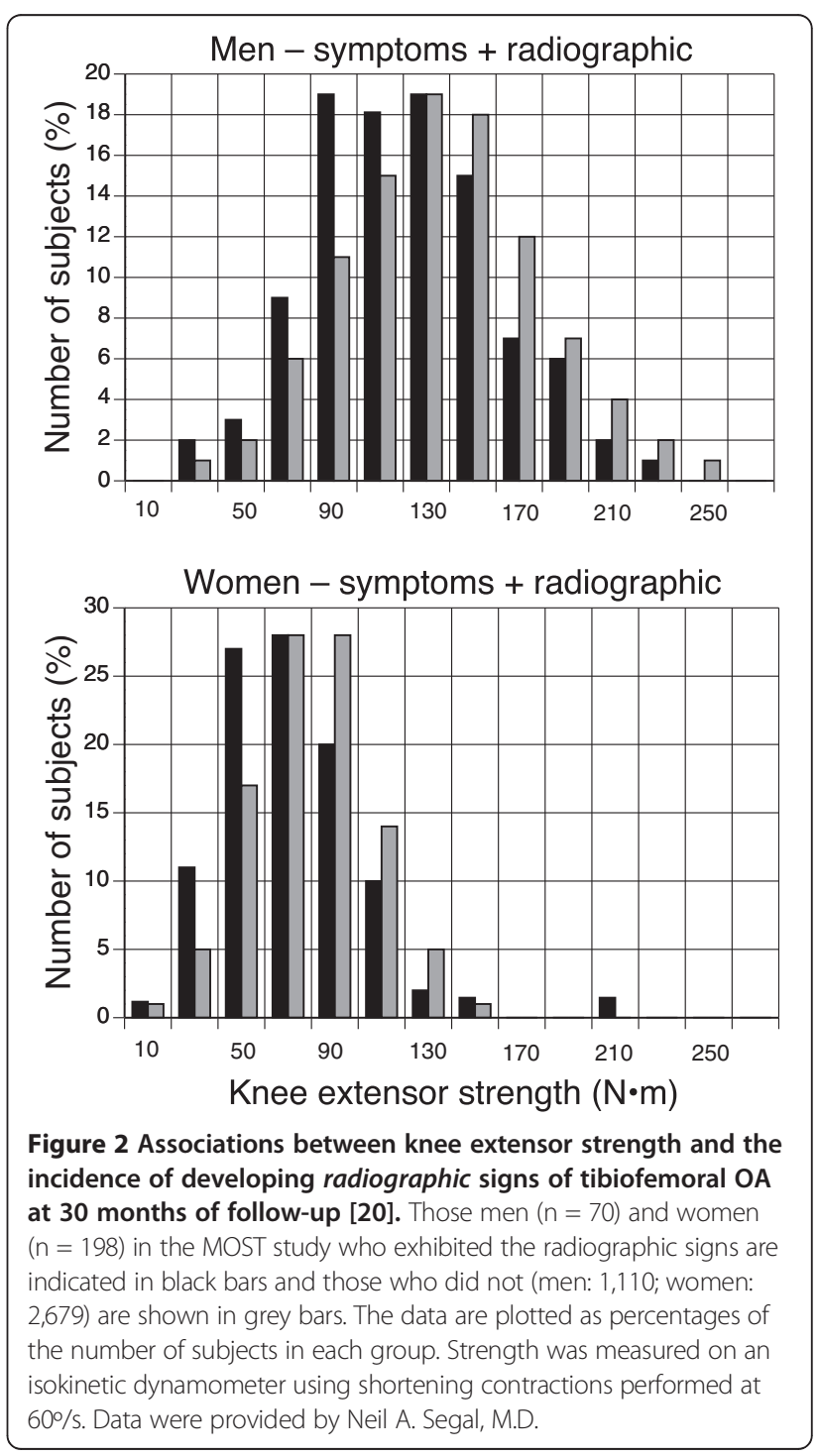




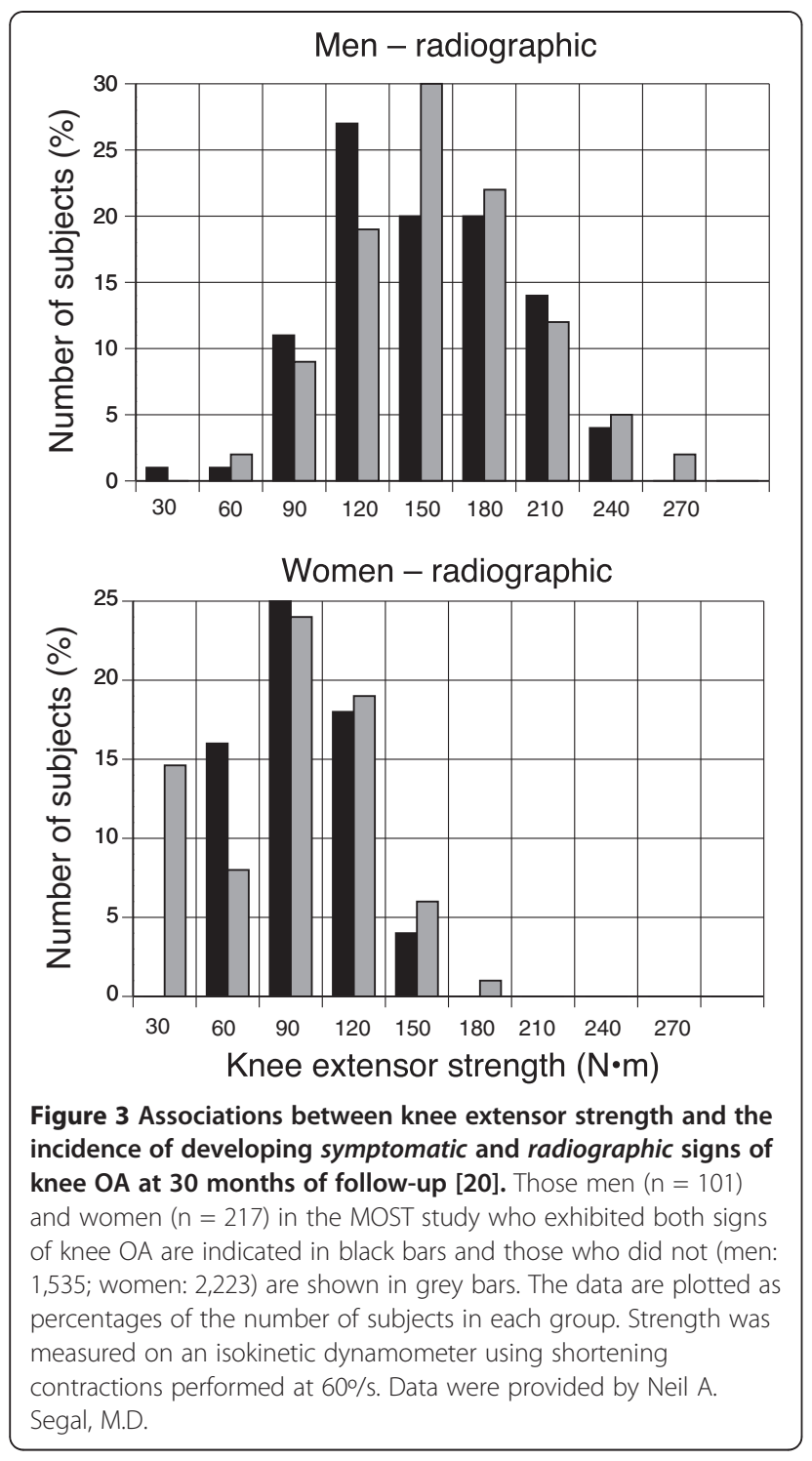

a subgroup of individuals (64.2 $\pm 7.4 \mathrm{yrs} ; \mathrm{n}=60,33$ women) from the MOST study who exhibited radiographic and symptomatic signs of knee OA produced 400-m walk times (215-537 s; $304 \pm 62$ s) that were associated with different muscle strength and gait characteristics for men and women [23]. The gait analysis comprised kinematic and ground reaction force measurements as participants walked at self-selected and controlled speeds along a 9-m walkway. Stepwise regression models indicated that some of the variability in walking speed (400-m walk times) for the men was explained by measures of the power produced in the sagittal plane by muscles that span the hip and ankle joints when walking at a moderate speed $(0.89 \mathrm{~m} / \mathrm{s})$ $\left(\mathrm{R}^{2}=0.32, P=0.025\right)$. The $400-\mathrm{m}$ walk times for men were also correlated with isokinetic strength of the knee extensors and flexors, but not the hip muscles (abduction, extension, flexion). In contrast, no measure of isokinetic strength for the knee (extension and flexion) or hip (abduction, extension, flexion) muscles was associated with 400-m walk times in women, but a significant amount of the variability in their 400-m walk times was explained by the torque and power about the hip (frontal plane) and knee (sagittal plane) joints when walking at the moderate speed $(0.89 \mathrm{~m} / \mathrm{s})\left(\mathrm{R}^{2}=0.61, P=0.003\right)$. Thus, the time taken to walk $400 \mathrm{~m}$, which provides an index of the repetitive loading of the knee joint, was associated with different measures of strength and mechanical output (torque and power) for lower limb muscles of men and women with similar levels of knee OA.

In people with symptomatic OA, walking speed $(400-\mathrm{m}$ walk times) decreased with age for the men and with the WOMAC pain score for women, but not with the Physical Activity Scale for the Elderly for either sex [23]. There were also modest-to-strong correlations between 400-m walk times and an index of lower limb function, the summary performance score for Short Performance Physical Performance Battery (SPPB), and 2-min walk distance. Furthermore, the torque and power produced by the knee muscles of men during walking did not differ with the level of functional mobility (composite SPPB score) and was similar to the findings reported for men without symptomatic knee OA. In contrast, higher functioning women exhibited greater ankle and hip (frontal plane) muscle activity during walking than those who were less mobile [23]. The findings indicated that men and women with greater mobility relied more on an ankle strategy than a hip strategy when walking, whereas men with less mobility decreased the ankle strategy and women with less mobility increased the hip strategy. Taken together, the results are consistent with the conclusion that higher functioning individuals with knee $\mathrm{OA}$ tend to modulate the mechanical output at the ankle more during walking than those who have more severe signs of knee OA and are less mobile [24], and that the more mobile women with knee OA had greater control of hip muscle activity in the frontal plane compared with lower functioning women $[25,26]$.

Relatively few studies have examined the predictive power of declines in muscle function, as reflected in tests of physical function, for the development of knee OA. Thorstensson et al. [27] followed 148 individuals (62 women; 35-54 yrs) with chronic knee pain for 5 yrs and found that the number of one-leg rises from a chair predicted the development of radiographic signs of knee OA (41/94 participants) $(\mathrm{OR} 2.6 ; 95 \% \mathrm{CI}=1.1-6.0)$. In contrast, progression of the radiographic signs in $29 / 54$ participants was not associated with any measure of physical function (leg rises, balance, 300-m walk). Furthermore, there were no sex differences between any of these associations. 
In summary, the data indicate that the strength of the knee extensors can predict the odds of developing symptomatic, but not radiographic, signs of knee OA in both men and women. Furthermore, the most mobile women with knee OA had greater function of the hip muscles in the frontal plane, whereas differences in mobility for both men and women were related to muscle function in the sagittal plane at the hip, knee, and ankle joints. It is not known, however, whether sex differences in muscle function either precede the development of knee OA or contribute to its progression. We identify several gaps in knowledge related to the potential influence of muscle function on the sex differences in knee OA (Table 3).

\section{Obesity}

Forces transmitted through the knee joint during walking can exceed four times body weight [28]. Consequently, increases in body weight, without associated compensatory adaptations in knee joint anatomy (e.g. subchondral bone) and limb kinematics and kinetics during movement (e.g. reduced stride length and walking speed, changes in knee adduction moments), would increase the stresses and strains in the knee joint during walking. Based on these associations, it has been hypothesized that the primary mechanisms by which obesity modulates knee joint integrity are through increases in joint loading and alterations in gait mechanics [29-31].

\section{Obesity as a predictor of the onset and progression of knee $O A$}

A number of observational studies have identified obesity as a risk factor for knee OA, with an increased risk for women compared with men. Body mass index (BMI) is a significant and independent predictor of the onset and progression of knee OA $[32,33]$ and this effect is stronger in women than in men [34]. In the Framingham study, the relative risk of developing knee OA in overweight individuals was 2.07 times greater for women and 1.51 times greater for men than for those individuals with the lowest body-weights [33]. In an investigation of 5,193 individuals from the first US National Health and Nutrition Examination Survey (HANES I), a life history of obesity increased the risk of developing knee OA later in life for women, whereas there was no such relation for men [35]. Similarly, the Genetics of Osteoarthritis and Lifestyle (GOAL) case-control study identified BMI as a factor that increased the risk of developing knee OA (OR 2.68), with the risk for knee OA being greater in women (OR 3.23) than in men (OR 2.20) [36].

However, an increase in physical activity, which presumably involved an increase in knee-joint loads, did not significantly increase or decrease the risk of developing knee OA in the Framingham cohort [37]. Interestingly, a measure of body shape, the waist-to-hip ratio, was independently associated with increased risk of hip but not knee OA in women [36], whereas the distribution of body fat was not related to either hip or knee OA in men [36]. However, obesity was associated with a younger age at the time of arthroplasty surgery independent of sex in a cohort of patients receiving total knee replacements [38] and the risk of developing lower limb OA was also greater in individuals who became overweight earlier in life. Obese children have altered gait patterns and knee kinematics compared with normal weight children that may lead to OA of the medial compartment of the knee due to increased medial compartment stresses resulting from greater peak internal knee-abduction moments [39].

\section{Obesity and limb alignment}

It has been hypothesized that the relation between BMI and knee OA may be mediated through changes in limb alignment suggesting that limb alignment is adaptable and a function of the biomechanical loading through the joint. Accordingly, BMI correlated with the severity of $\mathrm{OA}$ in knees with a varus alignment, but not those with a valgus alignment in a study of 292 individuals [40]. However, BMI also was significantly correlated with varus alignment and much of the variance in knee OA explained by BMI was also explained by varus alignment. In knees of 2,660 individuals from the MOST cohort without knee $\mathrm{OA}$ at baseline, the risk of developing radiographic signs of tibiofemoral OA at 30 months was significantly greater for overweight or obese subjects (defined by BMI) compared with normal-weight individuals, and this effect was not modified by limb alignment [41]. In this same study, however, subjects with $\mathrm{OA}$ at baseline exhibited no association between obesity and a worsening of the radiographic evidence of knee $\mathrm{OA}$ at 30 months when not accounting for limb alignment. When limb alignment was considered, obesity had no influence on OA progression in those individuals with baseline varus alignment, whereas BMI was significantly associated with OA progression among individuals with neutral or valgus alignment at baseline [41]. The data were not stratified by sex in these studies.

\section{Obesity and meniscus damage}

Increased joint loading due to obesity may also play a role in damage to the meniscus. Damage to or partial or complete removal of the meniscus is an established risk factor for knee OA [42-44]. Menisectomy (removal of the meniscus) results in altered load transmission through the knee joint and subsequent alterations in the stress and strain patterns in the knee cartilage tissue consistent with clinically observed patterns of cartilage damage $[45,46]$. In a study of 387 patients with meniscal tears, radial tears of the medial meniscus, which have been shown to result in a $25 \%$ increase in cartilage contact 
pressure and an increase in varus alignment compared to an intact knee [47], were associated with older age, females, and obesity [48]. Laberge et al. [49], in an analysis of MRI data of 137 individuals (45-55 years old) from the Osteoarthritis Initiative, found that the prevalence of meniscal lesions was $64 \%$, with a higher prevalence of meniscal tears in men (36\%) than women (13\%). Laberge et al. [49] also reported a nearly four-fold increase in meniscal tears in obese individuals compared with normal weight individuals, although this result was not stratified by sex [49].

\section{Obesity and systemic factors}

Although obesity may contribute to the risk of knee OA by increasing the loads experienced by the joint, obesity has also been associated with an increased risk of hand OA [50]. However, these data are equivocal with respect to sex. Although women have a greater risk of developing hand OA than men [51,52], a study that included both men and women showed a significant association between body weight and hand OA in men but not women [53], whereas a separate study of women only demonstrated that body weight was a significant predictor of incident hand OA [50]. Increasing evidence suggests that metabolic factors related to obesity, now regarded as a low-grade systemic inflammatory disease, influence systemic levels of cytokines, which interact with mechanical factors in the development of OA [54-57]. Individuals with OA have higher concentrations of leptin in synovial fluid and these levels are significantly correlated with BMI [58]. In addition, joint levels of leptin are greater in women compared with men [59]. Consistent with this hypothesis, a cross-sectional study investigating the effect of body mass composition (proportion of fat vs. muscle mass) on OA of 153 healthy subjects ranging from normal weight to obese found that body fat mass was positively associated with increased bone marrow lesions and cartilage defects (both are features of early knee OA), whereas there was no significant relation with skeletal muscle mass [60] suggesting that fat and muscle mass have differential effects on the development and progression of knee OA. In addition, an increase in physical activity for individuals with a BMI above the median within the Framingham cohort, which would imply increased mechanical loading within the knee joint, did not significantly increase (or reduce) the risk of knee OA [37]. These associations remain to be compared between the two sexes.

These results indicate that obesity is a significant risk factor for the development of knee OA, and that the association is stronger for women than for men. Although limb alignment does not contribute to the influence of obesity on incident knee OA, BMI does contribute to the progression of knee $\mathrm{OA}$ but only in neutral and valgus limbs. The mechanism by which obesity modulates OA appears to involve more than adverse changes in the local mechanical environment, likely involving synergistic systemic effects such as increases in inflammatory cytokines or alterations in hormone levels (see subsequent manuscript entitled "Hormonal Modulation of Connective Tissue Homeostasis and Sex Differences in Risk for Osteoarthritis of the Knee"). These interactions have not yet been compared between men and women and represent a significant gap in our understanding of the role sex differences play in the incidence and progression of knee OA. We identify several gaps in knowledge related to the influence of obesity on the sex differences in knee OA (Table 3).

\section{Conclusions}

Contact stress in knee-joint cartilage is a significant predictor of developing symptoms that are interpreted to

Table 3 Gaps in knowledge on the contributions of mechanical factors to sex differences in knee OA

\begin{tabular}{|c|c|}
\hline \multicolumn{2}{|c|}{ Limb Alignment } \\
\hline 1. & Are there sex differences in the prevalence of unilateral and bilateral limb alignment? \\
\hline 2. & How does limb alignment change across the lifespan for men and women? \\
\hline 3. & Are there sex differences in the prevalence of limb malalignment between obese men and obese women? \\
\hline \multicolumn{2}{|c|}{ Muscle Function } \\
\hline 1. & $\begin{array}{l}\text { Can strength training attenuate the incidence and progression of knee } O A \text { and is the intervention more or less effective in } \\
\text { women? }\end{array}$ \\
\hline 2. & $\begin{array}{l}\text { Do observed sex differences in muscle function during walking among individuals with knee OA contribute to either the } \\
\text { development or worsening of the disease? }\end{array}$ \\
\hline 3. & $\begin{array}{l}\text { What are the magnitudes of the cartilage stresses associated with differences in the mechanical output of lower limb } \\
\text { muscles observed in men and women with knee OA during walking? }\end{array}$ \\
\hline \multicolumn{2}{|c|}{ Obesity } \\
\hline 1. & $\begin{array}{l}\text { Does the differential influence of fat and muscle mass on the development and progression of knee OA differ for men and } \\
\text { women? }\end{array}$ \\
\hline 2. & Do circulating levels of inflammatory markers predict the sex difference in the prevalence of knee OA among older adults? \\
\hline 3. & Do meniscal lesions occur more frequently in men or women? \\
\hline
\end{tabular}


indicate the presence of knee OA. Limb alignment, as a surrogate measure that may modulate knee-joint mechanics, does not account for observed sex differences in the prevalence of knee OA. Although weakness of the knee extensor muscles is predictive of the incidence of symptomatic knee $\mathrm{OA}$, the association is similar for men and women. Nonetheless, the mechanical output of lower limb muscles (torque and power at the hip, knee, and ankle) during walking differs for low- and high-functioning individuals, with the differences depending on the sex of the individual. However, it is not known whether or not the sex differences in muscle function during walking contribute to either the development or progression of knee OA. Although, obesity poses a greater risk for developing knee OA in women than men, the mechanism is unknown.

The structural integrity of the articulating surfaces within the knee joint depends on the microstructural organization and material properties of the cartilage and meniscus, the macroscopic structural morphology of the joint (e.g., articular surface shape, cartilage thickness, joint alignment, ligament morphology, meniscus size and shape), and the loads transmitted through the joint. There are redundant combinations of traits through which joint configurations can provide nominally equivalent functionality under normal loading conditions. These combinations can involve quite different sets of traits, and a subset of these combinations, although sufficient for everyday loading environments, may be suboptimal when subjected to slight perturbations in one or more traits or loading conditions. Consequently, the development and progression of knee OA can result from multiple, distinct combinations of numerous musculoskeletal and neuromuscular traits. However, the dominant study design in research on knee OA focuses on the role of one or a limited set of factors that may contribute to the disease. There are significant gaps in knowledge about how different combinations of musculoskeletal, morphological, metabolic, and biological traits synergistically combine to provide lifelong, robust, knee function. To identify the mechanisms responsible for sex differences in the initiation and progression of knee OA, it may be necessary to take a more integrative approach of examining the interactions among a greater number of potential factors than is typical in most studies on knee OA

\section{Abbreviations}

BMI: Body mass index; Cl: Confidence interval; GOAL: Genetics of Osteoarthritis and Lifestyle; MOST: Multicenter Osteoarthritis Study; MRI: Magnetic resonance imaging; N: Newton; NHANES: National Health and Nutrition Examination Survey; OA: Osteoarthritis; OR: Odds ratio; SD: Standard deviation; SPPB: Short Performance Physical Performance Battery; WOMAC: Western Ontario and McMaster Universities Arthritis Index.

\section{Competing interests}

The authors declare that they have no competing interests.

\section{Authors' contributions}

All authors contributed to the development of the review. All authors read and approved the final manuscript.

\section{Acknowledgements}

This work was supported by a grant to the Society for Women's Health Research (SWHR) Isis Network on Musculoskeletal Health.

\section{Author details}

${ }^{1}$ Isis Research Network on Musculoskeletal Health, Society for Women's Health Research, Washington, DC 20036, USA. ${ }^{2}$ Mechanical Engineering Division, Southwest Research Institute, San Antonio, TX 78238, USA.

${ }^{3}$ Department of Orthopedic Surgery, Mayo Clinic, Jacksonville, FL 32224, USA. ${ }^{4}$ Department of Integrative Physiology, University of Colorado Boulder, Boulder, CO 80309, USA. 'Wallace H. Coulter Department of Biomedical Engineering, Georgia Institute of Technology, Atlanta, GA 30332, USA.

${ }^{6}$ Department of Surgery, University of Calgary, Calgary, AB T2N 4N1, Canada. ${ }^{7}$ Program of Neuroscience, Florida State University, Tallahassee, FL 32306, USA. ${ }^{8}$ Department of Physical Therapy and Rehabilitation Science, University of lowa, lowa City IA52242, USA. ${ }^{9}$ Division of Rheumatology and Clinical Immunology, University of Pittsburgh, Pittsburgh, PA 15261, USA.

${ }^{10}$ Department of Orthopedic Surgery and Pediatrics, George Washington University, Washington, DC 20010, USA. ${ }^{11}$ Department of Orthopedic Surgery, University of California, San Diego, San Diego, CA 92123, USA. ${ }^{12}$ Department of Genetics, Texas Biomedical Research Institute, San Antonio, TX 78245, USA. ${ }^{13}$ Division of Geriatric Medicine, University of Colorado Denver, Aurora, CO 80045, USA

Received: 12 July 2012 Accepted: 10 December 2012

Published: 23 December 2012

\section{References}

1. Brandt KD, Dieppe P, Radin E: Etiopathogenesis of osteoarthritis. Med Clin North Am 2009, 93:1-24. xv.

2. Segal NA, Anderson DD, lyer KS, Baker J, Torner JC, Lynch JA, Felson DT, Lewis CE, Brown TD: Baseline articular contact stress levels predict incident symptomatic knee osteoarthritis development in the MOST cohort. J Orthop Res 2009, 27:1562-1568.

3. Andriacchi TP, Mundermann A: The role of ambulatory mechanics in the initiation and progression of knee osteoarthritis. Curr Opin Rheumatol 2006, 18:514-518.

4. Mow VC, Ratcliffe A: Structure and function of articular cartilage and meniscus. In Basic orthopaedic biomechanics. 2nd edition. Edited by Mow VC, Hayes WC. New York: Lippincott Raven; 1997

5. Hsu RW, Himeno S, Coventry MB, Chao EY: Normal axial alignment of the lower extremity and load-bearing distribution at the knee. Clin Orthop Relat Res 1990, 255:215-227.

6. Sharma L, Hurwitz DE, Thonar EJ, Sum JA, Lenz ME, Dunlop DD, Schnitzer TJ, Kirwan-Mellis G, Andriacchi T: Knee adduction moment, serum hyaluronan level, and disease severity in medial tibiofemora osteoarthritis. Arthritis Rheum 1998, 41:1233-1240.

7. Bellemans J, Colyn W, Vandenneucker H, Victor J: The Chitranjan Ranawat Award: Is neutral mechanical alignment normal for all patients? The concept of constitutional varus. Clin Orthoped Related Res 2012, 470:45-53.

8. Sharma L, Song J, Dunlop D, Felson D, Lewis CE, Segal N, Torner J, Cooke TDV, Hietpas J, Lynch J, Nevitt M: Varus and valgus alignment and incident and progressive knee osteoarthritis. Ann Rheum Dis 2010, 69:1940-1945.

9. Brouwer GM, van Tol AW, Bergink AP, Belo JN, Bernsen RM, Reijman M, Pols HA, Bierma-Zeinstra SM: Association between valgus and varus alignment and the development and progression of radiographic osteoarthritis of the knee. Arthritis Rheum 2007, 56:1204-1211.

10. Hunter DJ, Niu J, Felson DT, Harvey WF, Gross KD, McCree P, Aliabadi P, Sack B, Zhang Y: Knee alignment does not predict incident osteoarthritis: The Framingham osteoarthritis study. Arthritis Rheum 2007, 56:1212-1218.

11. Yang NH, Canavan PK, Nayeb-Hashemi H: The effect of the frontal plane tibiofemoral angle and varus knee moment on the contact stress and strain at the knee cartilage. J Appl Biomech 2010, 26:432-443.

12. Sheehy L, Felson D, Zhang Y, Niu J, Lam Y-M, Segal N, Lynch J, Cooke TDV Does measurement of the anatomic axis consistently predict hip-knee- 
ankle angle (hka) for knee alignment studies in osteoarthritis? Analysis of long limb radiographs from the multicenter osteoarthritis (MOST) study. Osteoarthr Cartil 2010, 56:1212-1218.

13. Cooke D, Scudamore A, Li J, Wyss U, Bryant T, Costigan P: Axial lower-limb alignment: Comparison of knee geometry in normal volunteers and osteoarthritis patients. Osteoarthritis Cartilage Osteoarthritis Res Soc 1997, 5:39-47.

14. Hovinga KR, Lerner AL: Anatomic variations between Japanese and Caucasian populations in the healthy young adult knee joint. J Orthop Res 2009, 27:1191-1196.

15. Tang WM, Zhu YH, Chiu KY: Axial alignment of the lower extremity in Chinese adults. J Bone Joint Surg 2000, 82-A:1603-1608.

16. Tamari K, Tinley P, Briffa K, Aoyagi K: Ethnic-, gender-, and age-related differences in femorotibial angle, femoral antetorsion, and tibiofibular torsion: Cross-sectional study among healthy Japanese and Australian Caucasians. Clin Anat 2006, 19:59-67.

17. Pandy MG, Andriacchi TP: Muscle and joint function in human locomotion. Ann Rev Biomed Engin 2010, 12:401-433.

18. Baker KR, Xu L, Zhang Y, Nevitt M, Niu J, Aliabadi P, Yu W, Felson D: Quadriceps weakness and its relationship to tibiofemoral and patellofemoral knee osteoarthritis in Chinese: The Beijing osteoarthritis study. Arthritis Rheum 2004, 50:1815-1821.

19. Palmieri-Smith RM, Thomas AC, Karvonen-Gutierrez C, Sowers MF: Isometric quadriceps strength in women with mild, moderate, and severe knee osteoarthritis. Amer J Physical Med Rehab 2010, 89:541-548,

20. Segal NA, Torner JC, Felson D, Niu J, Sharma L, Lewis CE, Nevitt M: Effect of thigh strength on incident radiographic and symptomatic knee osteoarthritis in a longitudinal cohort. Arthritis Rheum 2009, 61:1210-1217.

21. Amin S, Baker K, Niu J, Clancy M, Goggins J, Guermazi A, Grigoryan M, Hunter DJ, Felson DT: Quadriceps strength and the risk of cartilage loss and symptom progression in knee osteoarthritis. Arthritis Rheum 2009, 60:189-198.

22. Brandt KD, Heilman DK, Slemenda C, Katz BP, Mazzuca SA, Braunstein EM, Byrd D: Quadriceps strength in women with radiographically progressive osteoarthritis of the knee and those with stable radiographic changes. J Rheum 1999, 26:2431-2437.

23. Segal NA, Yack HJ, Brubaker M, Torner JC, Wallace R: Association of dynamic joint power with functional limitations in older adults with symptomatic knee osteoarthritis. Arch Phys Med Rehab 2009, 90:1821-1828.

24. Astephen JL, Deluzio KJ, Caldwell GE, Dunbar MJ, Hubley-Kozey CL: Gait and neuromuscular pattern changes are associated with differences in knee osteoarthritis severity levels. J Biomech 2008, 41:868-876.

25. Briem K, Snyder-Mackler L: Proximal gait adaptations in medial knee OA. J Orthop Res 2009, 27:78-83.

26. Mundermann A, Dyrby CO, Andriacchi TP: Secondary gait changes in patients with medial compartment knee osteoarthritis: Increased load at the ankle, knee, and hip during walking. Arthritis Rheum 2005, 52:2835-2844

27. Thorstensson CA, Petersson IF, Jacobsson LT, Boegard TL, Roos EM: Reduced functional performance in the lower extremity predicted radiographic knee osteoarthritis five years later. Ann Rheum Dis 2004, 63:402-407.

28. Richards C, Higginson JS: Knee contact force in subjects with symmetrical OA grades: Differences between OA severities. J Biomech 2010, 43:2595-2600.

29. Messier SP, Gutekunst DJ, Davis C, DeVita P: Weight loss reduces knee-joint loads in overweight and obese older adults with knee osteoarthritis. Arthritis Rheum 2005, 52:2026-2032.

30. Gushue DL, Houck J, Lerner AL: Effects of childhood obesity on three-dimensional knee joint biomechanics during walking. $J$ Ped Orthoped 2005, 25:763-768

31. Sibella F, Galli M, Romei M, Montesano A, Crivellini M: Biomechanical analysis of sit-to-stand movement in normal and obese subjects. Clin Biomech 2003, 18:745-750.

32. Cooper C, Snow S, McAlindon TE, Kellingray S, Stuart B, Coggon D, Dieppe PA: Risk factors for the incidence and progression of radiographic knee osteoarthritis. Arthritis Rheum 2000, 43:995-1000.

33. Felson DT, Zhang Y, Hannan MT, Naimark A, Weissman B, Aliabadi P, Levy D: Risk factors for incident radiographic knee osteoarthritis in the elderly: The Framingham study. Arthritis Rheum 1997, 40:728-733.
34. Felson DT, Lawrence RC, Dieppe PA, Hirsch R, Helmick CG, Jordan JM, Kington RS, Lane NE, Nevitt MC, Zhang Y, Sowers M, McAlindon T, Spector TD, Poole AR, Yanovski SZ, Ateshian G, Sharma L, Buckwalter JA, Brandt KD, Fries JF: Osteoarthritis: New insights. Part 1: The disease and its risk factors. Ann Internal Med 2000, 133:635-646.

35. Anderson JJ, Felson DT: Factors associated with osteoarthritis of the knee in the first national health and nutrition examination survey (hanes i). Evidence for an association with overweight, race, and physical demands of work. Am J Epidem 1988, 128:179-189.

36. Holliday KL, McWilliams DF, Maciewicz RA, Muir KR, Zhang W, Doherty M: Lifetime body mass index, other anthropometric measures of obesity and risk of knee or hip osteoarthritis in the goal case-control study. Osteoarthritis Cartilage/OARS Osteoarthritis Res Soc 2011, 19:37-43.

37. Felson DT, Niu J, Clancy M, Sack B, Aliabadi P, Zhang Y: Effect of recreational physical activities on the development of knee osteoarthritis in older adults of different weights: The framingham study. Arthritis Rheum 2007, 57:6-12.

38. Gandhi R, Wasserstein D, Razak F, Davey JR, Mahomed NN: BMI independently predicts younger age at hip and knee replacement. Obesity 2010, 18:2362-2366.

39. Gushue DL, Houck J, Lerner AL: Effects of childhood obesity on three-dimensional knee joint biomechanics during walking. J Pediatr Orthop 2005, 25:763-768.

40. Sharma L, Lou C, Cahue S, Dunlop DD: The mechanism of the effect of obesity in knee osteoarthritis: The mediating role of malalignment. Arthritis Rheum 2000, 43:568-575.

41. Niu J, Zhang YQ, Torner J, Nevitt M, Lewis CE, Aliabadi P, Sack B, Clancy M, Sharma L, Felson DT: Is obesity a risk factor for progressive radiographic knee osteoarthritis? Arthritis Rheum 2009, 61:329-335.

42. Cicuttini FM, Forbes A, Yuanyuan W, Rush G, Stuckey SL: Rate of knee cartilage loss after partial meniscectomy. J Rheumatol 2002, 29:1954-1956

43. Englund M, Guermazi A, Roemer FW, Aliabadi P, Yang M, Lewis CE, Torner J, Nevitt MC, Sack B, Felson DT: Meniscal tear in knees without surgery and the development of radiographic osteoarthritis among middle-aged and elderly persons: The multicenter osteoarthritis study. Arthritis Rheum 2009, 60:831-839.

44. Englund M, Lohmander LS: Risk factors for symptomatic knee osteoarthritis fifteen to twenty-two years after meniscectomy. Arthritis Rheum 2004, 50:2811-2819.

45. Haemer JM, Song Y, Carter DR, Giori NJ: Changes in articular cartilage mechanics with meniscectomy: A novel image-based modeling approach and comparison to patterns of OA. J Biomech 2011, 44:2307-2312

46. Kurosawa H, Fukubayashi T, Nakajima H: Load-bearing mode of the knee joint: Physical behavior of the knee joint with or without menisci. Clin Orthop Related Res 1980, 149:283-290.

47. Allaire R, Muriuki M, Gilbertson L, Harner CD: Biomechanical consequences of a tear of the posterior root of the medial meniscus. Similar to total meniscectomy. J Bone Joint Surg Am 2008, 90:1922-1931.

48. Choi CJ, Choi YJ, Song IB, Choi CH: Characteristics of radial tears in the posterior horn of the medial meniscus compared to horizontal tears. Clin Orthop Surg 2011, 3:128-132.

49. Laberge MA, Baum T, Virayavanich W, Nardo L, Nevitt MC, Lynch J, McCulloch CE, Link TM: Obesity increases the prevalence and severity of focal knee abnormalities diagnosed using $3 T$ MRI in middle-aged subjects-data from the Osteoarthritis Initiative. Skeletal Radiol 2011, 41:633-641.

50. Oliveria SA, Felson DT, Cirillo PA, Reed Jl, Walker AM: Body weight, body mass index, and incident symptomatic osteoarthritis of the hand, hip, and knee. Epidemiology 1999, 10:161-166.

51. Srikanth VK, Fryer JL, Zhai G, Winzenberg TM, Hosmer D, Jones G: A meta-analysis of sex differences prevalence, incidence and severity of osteoarthritis. Osteoarthr Cartil 2005, 13:769-781.

52. Oliveria SA, Felson DT, Reed Il, Cirillo PA, Walker AM: Incidence of symptomatic hand, hip, and knee osteoarthritis among patients in a health maintenance organization. Arthritis Rheum 1995, 38:1134-1141.

53. Sayer AA, Poole J, Cox V, Kuh D, Hardy R, Wadsworth M, Cooper C: Weight from birth to 53 years: A longitudinal study of the influence on clinical hand osteoarthritis. Arthritis Rheum 2003, 48:1030-1033. 
54. Cicuttini FM, Baker JR, Spector TD: The association of obesity with osteoarthritis of the hand and knee in women: A twin study. J Rheumatol 1996, 23:1221-1226.

55. Griffin TM, Guilak F: Why is obesity associated with osteoarthritis? Insights from mouse models of obesity. Biorheology 2008, 45:387-398.

56. Goldring MB, Otero M: Inflammation in osteoarthritis. Curr Opin Rheumatol 2011, 23:471-478.

57. McNulty AL, Miller MR, O'Connor SK, Guilak F: The effects of adipokines on cartilage and meniscus catabolism. Connect Tissue Res 2011, 52:523-533.

58. Dumond H, Presle N, Terlain B, Mainard D, Loeuille D, Netter P, Pottie P: Evidence for a key role of leptin in osteoarthritis. Arthritis Rheum 2003, 48:3118-3129.

59. Presle N, Pottie P, Dumond H, Guillaume C, Lapicque F, Pallu S, Mainard D, Netter $P$, Terlain B: Differential distribution of adipokines between serum and synovial fluid in patients with osteoarthritis. Contribution of joint tissues to their articular production. Osteoarthr Cartil 2006, 14:690-695.

60. Berry PA, Wluka AE, Davies-Tuck ML, Wang Y Strauss BJ, Dixon JB, Proietto J, Jones G, Cicuttini FM: The relationship between body composition and structural changes at the knee. Rheumatol (Oxford) 2010, 49:2362-2369.

61. Yang: The effect of the frontal plane tibiofemoral angle on the contact stress and strain at the knee joint. Ph.D. dissertation: Department of Mechanical and Industrial Engineering. Chicago, IL: Northeastern University; 2009.

doi:10.1186/2042-6410-3-28

Cite this article as: Nicolella et al: Mechanical contributors to sex differences in idiopathic knee osteoarthritis. Biology of Sex Differences 2012 3:28.

\section{Submit your next manuscript to BioMed Central and take full advantage of:}

- Convenient online submission

- Thorough peer review

- No space constraints or color figure charges

- Immediate publication on acceptance

- Inclusion in PubMed, CAS, Scopus and Google Scholar

- Research which is freely available for redistribution 